Proceedings

\title{
Smart Glove with an Arduino-Controlled Textile Bending Sensor, Textile Data Conductors and Feedback Using LED-FSDs $^{\mathrm{TM}}$ and Embroidery Technology ${ }^{\dagger}$
}

\author{
Ramona Nolden *, Kerstin Zöll and Anne Schwarz-Pfeiffer
}

Citation: Nolden, R.; Zöll, K. Schwarz-Pfeiffer, A. Smart Glove with an Arduino-Controlled Textile Bending Sensor, Textile Data Conductors and Feedback Using LED-FSDs ${ }^{\mathrm{TM}}$ and Embroidery Technology. 2021, 68, 4 . https://doi.org/10.3390/ proceedings2021068004

Published: 5 January 2021

Publisher's Note: MDPI stays neutral with regard to jurisdictional claims in published maps and institutional affiliations.

Copyright: $@ 2021$ by the authors. Licensee MDPI, Basel, Switzerland. This article is an open access article distributed under the terms and conditions of the Creative Commons Attribution (CC BY) license (http://creativecommons.org/licenses/by/4.0/).
Department for Textile and Clothing Technology, Research Institute for Textile and Clothing, Hochschule Niederrhein-University of Applied Sciences, Webschulstraße 31, 41065 Mönchengladbach, Germany; Kerstin.Zoell@hs-niederrhein.de (K.Z.); Anne.Schwarz-Pfeiffer@hs-niederrhein.de (A.S.-P.)

* Correspondence: Ramona.Nolden@hs-niederrhein.de

+ Presented at the International Conference on the Challenges, Opportunities, Innovations and Applications in Electronic Textiles (E-Textiles 2020), Virtual venue, UK, 4 November 2020.

\begin{abstract}
The smart glove presented in this paper consists of an integrated textile bending sensor in the finger; functional sequins, called LED-FSDs ${ }^{\mathrm{TM}}$, on the back of the hand; an attachable cuff with a microcontroller and an energy source. The glove and the cuff are connected by small push buttons. The signals derived from the textile bending sensor are controlled by the microcontroller in the cuff and forwarded to the acting LED-FSDs ${ }^{\mathrm{TM}}$. All components are connected to each other by a silvercoated, electro conductive thread, which is processed by a fully automated and reproducible embroidery process.
\end{abstract}

Keywords: smart glove; textile bending sensor; LED-Functional Sequin Devices; embroidery process; biofeedback; rehabilitation device; therapy glove

\section{Introduction}

The smart textile market is growing rapidly thanks to the advancing miniaturization of electronics and numerous industrial applications. Currently, the global market value for intelligent, digital and interactive fabrics and textiles is around $\$ 2$ billion [1]. In particular, since smart textiles do not change the perception of garments in contrast to portable devices, they enable a wide range of technological research. Using embroidery technology, a large number of textile sensors and actuators are already being produced in sports and medical technology. In the latter application field, numerous products, such as monitoring shirts, heating bandages and therapy gloves, have been presented. Technical embroidery is becoming increasingly important for their development and production [1,2].

Therapy gloves for finger training are already used for nerve stimulation for improving the sense of touch and the mobility of the hand in rehabilitation after brain damage via built-in electrodes at the fingertips [3] and for pain therapy (TENS) [4]. Furthermore, high-precision sensors can transmit the movement of the finger joints to software in real time and visually display it to the user and therapist as biofeedback [5]. However, these current therapy gloves actively contribute to rehabilitation only by using an external power source [3], impulse generator or software connection [5] and often do not integrate feedback for learning success control and increasing motivation to train and exercise [4]. External sensory and/ or data management devices mounted on top of the gloves limit the practical exercises and make it difficult for the user to successfully exercise with them.

Against this background, the main aim of this research was the development of a textile-integrated solution for the monitoring of finger movements with a smart glove and providing feedback to the wearer during the rehabilitation process. The developed smart 
glove consists of an integrated bending sensor in the finger, LED-Functional Sequin Devices on the back of the hand to provide optical feedback to the wearer and an attachable cuff with integrated power source and a signal controlling microcontroller.

\section{Materials and Methods}

\subsection{Base Fabric}

The chosen fabric for the glove and the cuff is an elastic neoprene fabric obtained from Extremtextil e.K., Germany. The neoprene is $1.5 \mathrm{~mm}$ thick and made of chloroprene rubber, laminated on both sides with polyester jersey.

\subsection{Materials for the Textile Bending Sensor}

The textile bending sensor is based on the piezoresistive measuring principle (Figure 1). This sensor principle is generated through the change in electrical resistance due to the action of a force. The three layers of the textile bending sensor consists of two embroidered electrode layers using a silver-coated polyamide sewing thread with a fineness of dtex 117 $\times 2$ (HC 40 from Madeira Garnfabrik, Germany) separated by one layer of conductive and carbon impregnated polyethylene film (Velostat ${ }^{\mathrm{TM}}$ from $3 \mathrm{M}$ ).

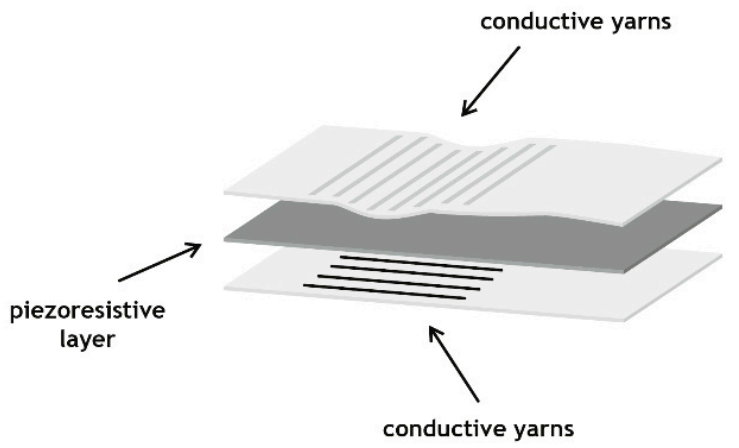

Figure 1. Schematic illustration of the piezoresistive textile bending sensor.

\subsection{Materials for Textile Data Transmission Lines}

The silver-coated polyamide embroidery thread, brand name HC 40 from Madeira Garnfabrik, Germany, was also used to serve as transmission lines within the electrical network of the smart glove. It consists of $100 \%$ polyamide and is fully silvered and known by the name Shieldex ${ }^{\circledR}$ from Statex. The electrical resistance of the thread is less than 300 $\Omega / \mathrm{m}$. It can be machine washed at $30^{\circ} \mathrm{C}$ and is certified according to Öko-Tex ${ }^{\circledR}$ Standard 100 .

\subsection{Functional Sequin Devices}

The Functional Sequin Devices (FSDs ${ }^{\mathrm{TM}}$ ) are conventional plastic sequins that are carriers of small electronic components, such as light emitting diodes (as in our case) [6]. They can be placed individually on the fabric using embroidery technology in an automated process, attached with conventional embroidery thread and contacted with a conductive embroidery thread.

\subsection{Microcontroller and Arduino IDE Code}

In the presented smart glove, the Lilypad simple board is used as a processor and programming adapter. It is compatible with Arduino IDE. The Lilypad simple board controls the input signal of the finger bending sensor, evaluates the incoming signal and transmits it as an output signal for visualization to the acting LED-FSDs ${ }^{\mathrm{TM}}$. Arduino is an open source software and consists of hardware and software with a special programming 
language to a physical computing platform. The code for the textile bending sensor is based on three threshold values of the resistance, with bending tendencies from $45^{\circ}$ up to and $135^{\circ}$, corresponding to the three integrated LEDs-FSDs ${ }^{\mathrm{TM}}$.

\subsection{Embroidery Process and Parameters}

A multifunctional portal-embroidery machine (type SGVA) with three embroidery heads, the F-, K- and W-head from ZSK Stickmaschinen GmbH, Germany, is used to process the silver-coated embroidery threads as well as the LED-FSDs ${ }^{\mathrm{TM}}$. The transmission lines are produced by using the F-Head, which is a multi-needle head. It is based on a two-thread system, and the stitch type is the double lockstitch. In order to achieve a low electrical resistance of the textile data transmission lines, three overlapping zig-zag double lockstitch seam lines are embroidered and covered with a standard embroidery thread to protect against external influences. The F-head is also applied to place and fix the Functional Sequin Devices through a fully automated process and also the microcontroller in a semi-automatic process.

\section{Results and Discussion}

The smart glove is manufactured in one size. Therefore, it is designed as a fingerless glove with adjustable Velcro straps. The index finger plays an essential role, as it is the most frequently used of all fingers. Moreover, it can be moved relatively independently, just like the thumb and little finger. Accordingly, the bending sensor is integrated in the index finger (Figure 2). The LED-FSDs ${ }^{\mathrm{TM}}$ are located on the back of the hand so that they are visible to the user, no matter what finger movements are made. To make the glove washable, a removable cuff is used to protect the electronic components that are not waterproof. Thus, the Lilypad simple board can be fitted and concealed on the inside of the cuff. The contact in the pins is via conductive lines, which end in small, circular, conductive areas. On the glove design, there are identical circular areas at the ends of the conductive transmission lines, so that the cuff and the glove can be connected by small push buttons (Prym Consumer Europe GmbH, Germany). They have a very good mechanical bonding strength and conductivity. The circular areas are offset next to each other so that the push buttons cannot touch each other.

The textile bending sensor reacts according to the bending tendency. Three programmed bending states can be implemented. When the finger is extended, all LEDs are off. With a slight bending of approximately $45^{\circ}$, one LED will shine. Two LEDs are activated with an average bending of approximately $90^{\circ}$, and all LEDs light up with a complete bending of the finger up to $135^{\circ}$.
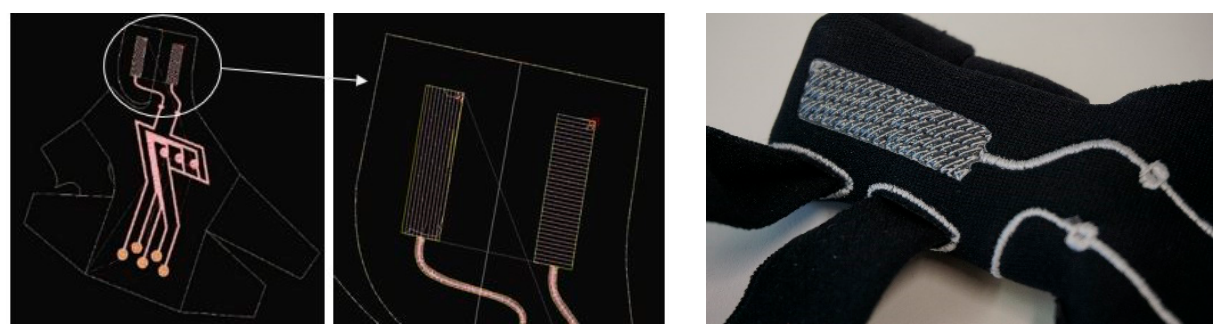

Figure 2. Piezoresistive textile bending sensor (left: punch pattern, right: final bending sensor).

During the finger training, the bending sensor may slip sideways. This leads to changed threshold values, which causes the LED-FSDs ${ }^{\mathrm{TM}}$ to react more sensitively and not according the programmed bending values. If the fixation on the finger is set too tight, the sensor cannot slip, but the neoprene exerts pressure on the sensor and the first LED already lights up when the finger is stretched. A thinner and more pliable sensor design would adapt better to the geometry of the finger and thus provide more consistent measurement results and transmissions of the bending sensor. 


\section{Conclusions}

The smart glove (Figure 3) categorized as smart textile with a textile sensor system in combination with electronic components is a promising technology in the field of medical technology. It enables the mobile sensory detection of motion mobility of the fingers and can be used as a therapeutic measure and rehabilitation for the treatment of osteoarthritis, finger fractures, capsule and tendon injuries and finger stiffness. In addition to finger training, the smart glove also provides feedback by visualizing the motion signals using the LED-Functional Sequin Devices ${ }^{\mathrm{TM}}$. The feedback signalizes the success of the therapy to the operator, acts as a self-control over the motion training process and increases the motivation and the learning process. Due to the wireless conception and implementation, finger training can be carried out anytime and anywhere.
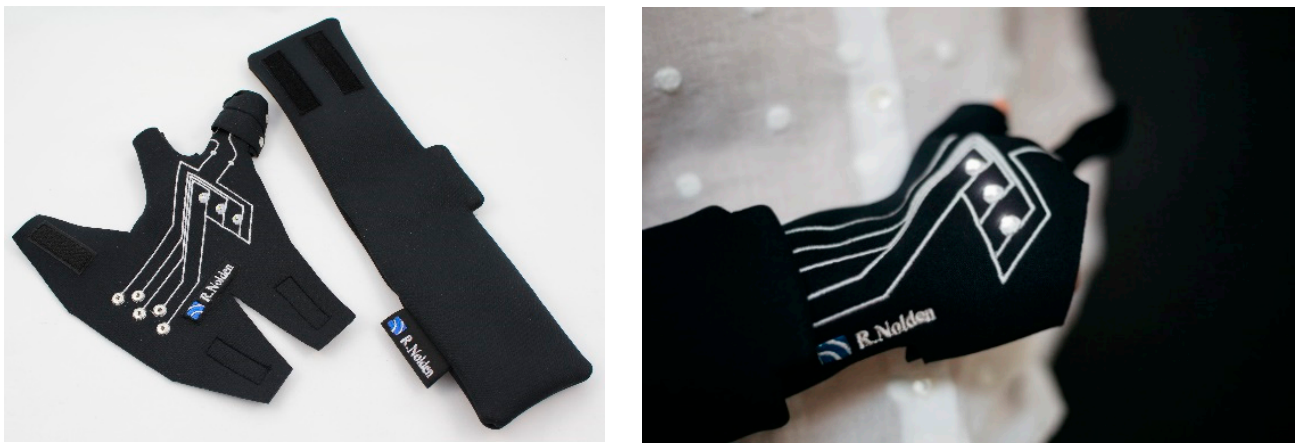

Figure 3. Smart glove and cuff; when forming a wrist, the LEDs light up giving feedback on the intensity of the bending of single fingers.

The application, which is currently limited to finger and mobility training with feedback, would be conceivable in combination with the technology of nerve stimulation for pain therapy (TENS). Finger training could be used to increase mobility with simultaneous stimulation of the fingers through integrated textile electrodes to improve the sense of touch and additional feedback to control learning success and increase motivation.

Funding: This research received no external funding.

\section{References}

1. Koncar, V. Smart Textiles and Their Applications, Woodhead Publishing; Elsevier: Amsterdam, The Netherlands, 2016; pp. 1-5.

2. Hanus, S. Textile Solutions for Medicine, Medical Technology, Sport and Wellness; TITV Textilforschungsinstitut Thüringen Vogtland e. V.: Weimar, Germany, 2013.

3. BOSANA Medizintechnik GmbH, TIPSTIM ${ }^{\circledR}$. 2020. Available online: https://www.tipstim.de/ (accessed on 14 September 2020).

4. tic Medizintechnik GmbH \& Co. KG, TENS Glove. 2020. Available online: https://saneostore.de/Stimulationshandschuh/tiHC884A (accessed on 14 September 2020).

5. SVG Rehasysteme GmbH \& Co. KG, HandTutor ${ }^{\mathrm{TM}}$. 2020. Available online: https://www.svg-rehasysteme.de/handtutor/ (accessed on 14 September 2020).

6. Imbut GmbH. FSD Functional Sequin Device. Available online: https://www.imbut.de/images/pdf/Functional_Sequin_Devicedt.pdf (accessed on 20 March 2020). 